\title{
Modeling and assessment of polychlorinated biphenyls contamination in soil at a burial site of power capacitors
}

\author{
H. Wang $\cdot$ J. Chen
}

Received: 7 July 2011/Revised: 13 November 2011 / Accepted: 22 May 2012/Published online: 6 March 2013

(C) Islamic Azad University (IAU) 2013

\begin{abstract}
Numerous industrial or burial sites contaminated by persistent organic pollutants such as polychlorinated biphenyls (PCBs) and pesticides were discovered in China recently. Due to improper choice of technology, many remediation cases had cost too much; however, failed to attain expected goals. In this study, the distribution and transport of PCBs at a burial site were investigated using tested PCBs concentration in order to support the choice of remediation technology and estimate the remediation results. Site characterization was carried out in order to investigate the hydrogeological condition and PCBs pollution nearby the capacitor burial site located in Shanxi, China. Results of PCBs measurement indicated that the proportion of contaminated soil with concentration above $500 \mathrm{mg} / \mathrm{kg}$ is $7.8 \%$ and the value for soil with concentration between 50 and $500 \mathrm{mg} / \mathrm{kg}$ is $18.0 \%$. Considering adsorption and biodegradation, the two-dimensional PCBs transport model was established based on advection-dispersion equation. The model calibration showed a good agreement between measured and computed values, indicating the feasibility of this model used for predicting the transport and disappearance of PCBs in soil. Results of 100 years' simulation demonstrated the slow migration and biodegradation of PCBs. Simulations were conducted for before and after remediation scenarios. Comparison of the results indicates that the remediation alternatives of
\end{abstract}

H. Wang $\cdot$ J. Chen $(\bowtie)$

Key Laboratory for Water and Sediment Sciences of Ministry of Education, School of Environment, Beijing Normal University, 100875 Beijing, China

e-mail: jeffchen@bnu.edu.cn

H. Wang

bCECEP L\&T Environmental Technology Co., Ltd,

Beijing, China excavation-incineration and thermal desorption have successfully removed most of the organics and thus reduced the environmental risk to a low level.

Keywords Polychlorinated biphenyls (PCBs) . Remediation · Soil-water distribution · Transport modeling

\section{Introduction}

Polychlorinated biphenyls (PCBs) have been widely used as coolants and lubricants in transformers, capacitors and other electrical equipment because of their insulating and nonflammable properties (Fouial-Djebbar et al. 2010). PCBs are a family of synthetic organic compounds with general chemical formula $\mathrm{C}_{12} \mathrm{H}_{10-n} \mathrm{Cl}_{n}$ with $n$ ranging between 1 and 10. As a consequence 209 different configurations or congeners are possible (USEPA 1987a; Shikiya et al. 1988). Each PCB congener is named according to the positions of chlorine substitution on the two rings of biphenyl and it is identified with numbers ranging from 1 to 209 (Ballschmiter and Zell 1980). For different social and economic reasons, significant quantities of capacitors which contain PCBs oil are still in use or in storage (The Environment Programme of the United Nations 1998, 2000). Leakage of removed power capacitors containing a high concentration of PCBs always leads to serious soil contamination. In fact, the potential leakage of PCBs poses serious threat to the humans and the ecosystem (Blais et al. 1998; Fagbote and Olanipekun 2010). The USEPA has calculated prudent public health levels that maintain PCB exposures below the "reference dose"- the amount of PCB exposure that EPA does not believe will cause harm. EPA's reference dose (RfD) is $20 \mathrm{ng}$ PCB/kg body weight per day (USEPA 1987b). In the 
1970s, China's Ministry of Machinery announced a ban on production of capacitors containing PCBs and subsequently called for gradual phaseout of these capacitors within a definite time frame. The used capacitors were then buried underground or sealed in some caves as no other effective treatment alternatives were available.

In 1979 several batches of retired capacitors which contain large amounts of insulating oil were buried at a hillside in an area of northern China. According to the laboratory test, the Aroclor 1242 content of insulating oil was more than $70 \%(\mathrm{v} / \mathrm{v})$ (Lu 2009). Because of unintended spill or leakage, a great quantity of soil down the burial site was severely contaminated. And humans and livestock about $150 \mathrm{~m}$ away from the burial site were exposed to contamination. The release of PCBs into the environment presents a threat due to their persistency and toxicity. The toxic effects are compounded by the hydrophobicity of PCBs, causing them to bio-accumulate in the tissues of plants, animals and finally, humans (Monosson et al. 2003; Cok and Satiroglu 2004). For this reason the local power sector planned to carry out site remediation to remove the PCBs contaminants in this area. PCBs distribution was studied in order to calculate the amount of soil with different contamination level. The results were used to make a choice between incineration and thermal desorption, which were two common technologies for persistent organic pollutants (POPs) treatment in China ( $\mathrm{Li}$ et al. 2004).

Convection and dispersion equation is one of the most popular models used for simulating the migration and transformation of heavy metals, organics, and radionuclides. Preliminary studies indicate that the solute transport model is effective in simulating the transport of pesticide and heavy metal (Ismail and Ngan 2004; Fava and Orru 2005; Chatupote and Paapitukkul 2005; Devasena and Nambi 2010). A few simulations have been conducted with columns data acquired from experiments under lab or semifield conditions. Hodak Kobasic et al. (2008) used the natural soil contaminated by Aroclor 1248 to conduct the leaching experiment. The study shows large amounts of PCBs loss in the upper layer soil due to evaporation and accumulation of PCBs in the deepest layer of soil, probably because of the vertical transport of the PCBs and the lack of volatilization. Zhu and Xia (2003) make use of the artificially contaminated soil to estimate the transport and biodegradation of PCBs. The results indicate a very slow speed of PCBs' migration in soil, although the adsorption of contaminants onto the artificial soil is weaker than the actual soil. However, research data on water flow and PCBs transport around the contaminated sites are very scattered. Additionally, numerical models were seldom used for predicting the transport and disappearance at an actual contaminated site ( $\mathrm{Li}$ and Chen 2010). The magnitude of rainfall, soil-water distribution coefficient $\left(K_{\mathrm{d}}\right)$ and degradation rate are known to be dominant controls on organics migration and disappearance. A better understanding of different distribution between contaminated and remediated soils is required to investigate the effectiveness of rehabilitation work and the feasibility of solute transport model as a risk assessment method. Therefore, this study begins with a calibration of the 2-D solute transport model on simulating the transport and biodegradation of PCBs in one of the burial sites (pit 1). The emphasis here is to make a comparison between contaminated and remediated soils on PCBs transport under semiarid conditions in northern China. The PCBs measurement could offer a scientific basis for the selection of proper treatment technology and measures and simulation results can provide the basic data and information for the ecological risk assessment of PCBs and homologous organics.

\section{Materials and methods}

\section{Site characterization}

The capacitors' burial site was located at a mountainous region, where gullies have well taken shape over the ages, contributing to a sharply dissected topography with heaving and rolling slopes. The entire terrain is more elevated in the west and in the south, the overall altitude being $1,100-1,300 \mathrm{~m}$. The burial site was close to a ridge road and the crow-fly distance between the site and the nearest village, the Longwan Temple was within $150 \mathrm{~m}$ (Fig. 1a).

The geophysical prospecting results indicated that the quaternary sedimentary formation of upper soil and the lithology was silty clay. The upper silty clay containing plant roots appears to be yellow or pale yellow with a thickness of $0.8-1.0 \mathrm{~m}$. The lower silty clay appeared to be dark red with a thickness of 1.7-2.0 m (with tight structure and high hardness). The lower sandy clay appears to be light red with a thickness of $0.9-1.2 \mathrm{~m}$. Based on a detailed study the soil where capacitors were buried was identified as MaLan Unit (Q3m) (Zhou, 1988). The fact that no groundwater was discovered in drilling bores indicated that the water table was beyond $9 \mathrm{~m}$ below surface. The study area was located in a typical semiarid area of China and the yearly precipitation was between 500 and $700 \mathrm{~mm}$ during the last 30 years.

The burial site (pit 1) was marked in Fig. 1b with a horizontal size of $1 \mathrm{~m} \times 2 \mathrm{~m}$. Several capacitors with the size of $0.75 \mathrm{~m} \times 0.75 \mathrm{~m} \times 0.75 \mathrm{~m}$ were sealed by iron sheet and buried in this field 30 years ago. Through on-site geophysical prospecting, the buried capacitors were found to have been stolen. It was the dispersion of soil particle, broken cement layer and the leakage of PCBs oil caused by 
Fig. 1 a Location of burial site, $\mathbf{b}$ horizontal distribution of drilling bores, $\mathbf{c}$ concept model for water movement
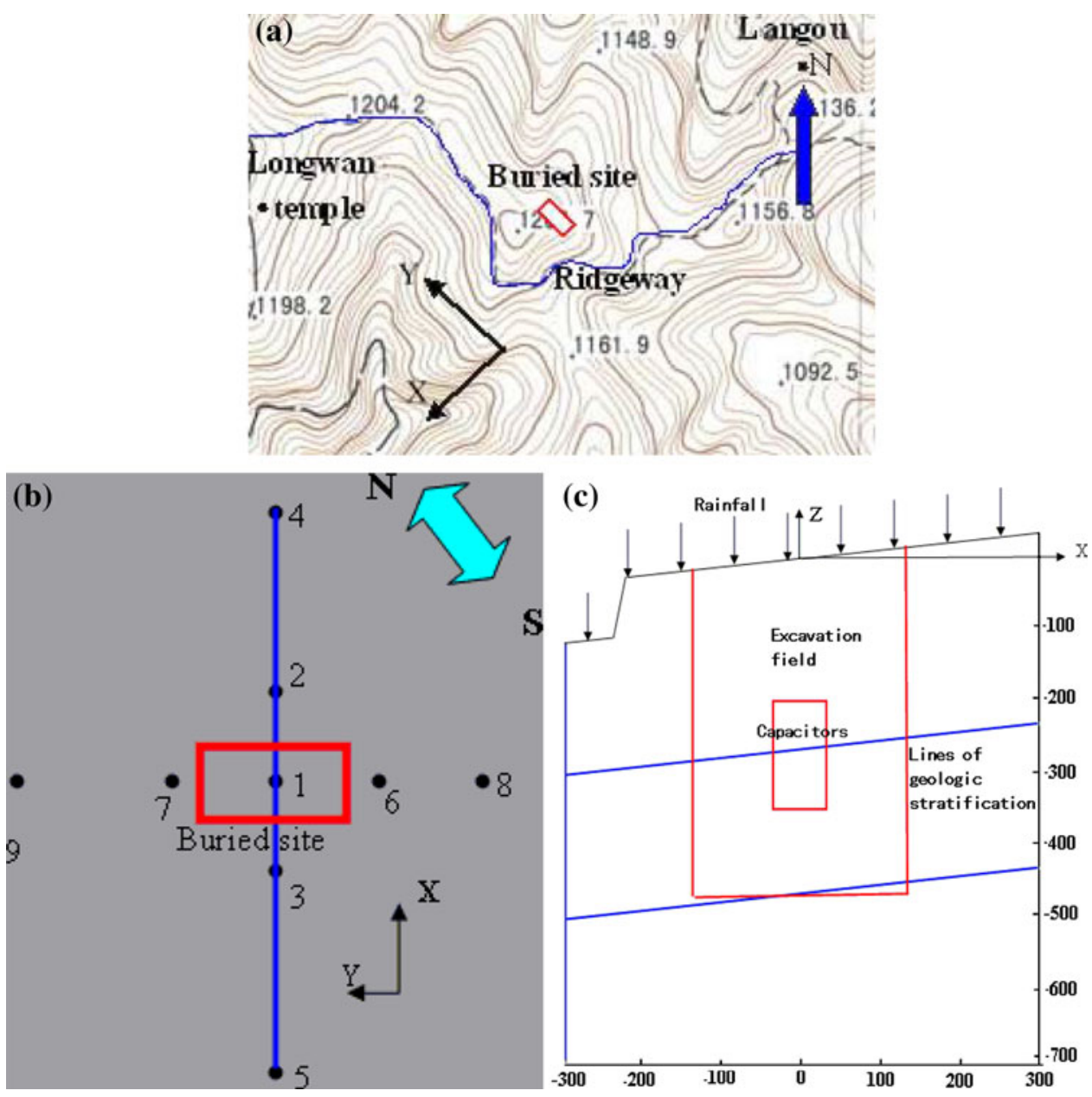

stealing that leads to the serious contamination of soil. Field drilling which provides the opportunity for soil sampling in order to implement site characterization was carried out among or around the buried capacitors. The depth of each bore was within 8-9 m. The $x$ and $y$ coordinates were set up, as shown in Fig. 1. $Z$ direction was vertical to horizontal plane. Soils along the $x$ and $z$ directions were preferentially sampled due to the 2-D simulation in profile.

\section{Hydrogeological description}

Hydraulic conductivity of soil in different geological strata was measured by laboratory experiments. Soil samples were separated into fractions of three different sizes $(<50$, $50-75,75-250 \mu \mathrm{m})$ by dry sieving. The mass of each soil size fraction was weighed to calculate the mass fraction. The size fractions $<50 \mu \mathrm{m}$ soil were further separated into three fractions $(<5,5-10,10-50 \mu \mathrm{m})$ by hydrometer method. The test results of physical-chemical characteristics and texture of the soil showed that with the increase of matrix depth, fine fraction of particulates increases and hydraulic conductivity decreases.
The soil moisture at different depths was tested using oven drying method. Characteristic curve of soil moisture was tested by means of ceramic plate extractor (model 1500F, 15,000 hpa). Data fits to Van Genuchten formula for different soils were good and the coefficients in Van Genuchten formula were gained for simulation. A program written in FORTRAN was used to conduct the data fit.

Under the hydrogeological condition, water flow and PCBs transport in the unsaturated zone are dominated in vertical direction by gravity with some longitudinal flow and transport down slope also by gravity. Samplings by drilling were conducted at positions near and around the burial site and numerical simulation of 2-D flow and transport in profile will be conducted. Simulation area was determined as a $6 \mathrm{~m} \times 7 \mathrm{~m}$ profile with an area of $42 \mathrm{~m}^{2}$. In this study, existence of multiscale heterogeneity which comprises water content, relative permeability and macro dispersivity motivated an analysis based on different geologic stratifications (three stratifications divided by two blue lines shown in Fig. 1c). The surface slope was $6^{\circ}$ and the conception model for water movement is depicted in Fig. 1c. 
PCB sampling and analysis

\section{PCBs sampling}

PCBs sampling was performed via drilling. The distribution of nine drilling bores in or around pit 1 is shown in Fig. 1a

\section{PCBs analysis}

Chemical reagents Aroclor 1242 and PCB209 (decachlorobiphenyl) dissolved in hexane $(1 \mathrm{mg} / \mathrm{mL})$ were obtained from Accu-Standard Inc. (AccuStandard, USA), and internal standard 1-Bromo-2-nitrobenzene(BNB) was obtained from Sigma Co. (Sigma, USA). Anhydrous sodium sulfate, diatomite, Florisil cartridges $(1 \mathrm{~g}, 6 \mathrm{~mL})$ and copper powder were analytical grades obtained from the Beijing Chemical Reagents Company, China. All solvents used for sample processing and analysis (acetone and hexane) were HPLC grades purchased from J. T. Baker (Phillipsburg, NJ, USA). Deionized water was produced by a Milli-Q system (Millipore Co., USA).

PCBs extraction and clean up The PCBs in the contaminated soil were extracted with an acetone and hexane mixture $(1: 1, \mathrm{v}: \mathrm{v})$ with an accelerated solvent extractor (ASE 300, Dionex Corp.). $1.0 \mathrm{~g}$ of dried, homogenized soil of the bulk soil was mixed with diatomite and activated copper powder, then filled into the stainless steel extraction cells. Prior to extraction, the soil was spiked with recovery surrogate standards of Aroclor $1242(1 \mathrm{~mL}, 10 \mathrm{mg} / \mathrm{L})$ and PCB209 $(1 \mathrm{~mL}, 1 \mathrm{mg} / \mathrm{L})$. The extracts were concentrated to near dryness by rotary evaporation and changed into solvent of hexane for further cartridge separation.

PCBs in concentrated hexane extract were separated by using Florisil cartridges with $1 \mathrm{~g}$ anhydrous sodium sulfate overlaying the alumina to remove small quantities of water. The first step in doing this was: Add $12 \mathrm{~mL}$ of hexane to clean and activate the column. Close cartridge valves when there was still at least $1 \mathrm{~mm}$ of solvent above the sorbent bed. The second step: quantitatively transfer the $1.0 \mathrm{~mL}$ sample extract onto the column using an additional $2 \mathrm{~mL}$ of hexane to complete the transfer and then turn on the valve. And the third step: Add $2 \mathrm{~mL}$ hexane/acetone (9:1, $\mathrm{v}: \mathrm{v})$ and then turn on the valve $1.0 \mathrm{~min}$ later. At the same time collect the eluate using $10 \mathrm{~mL}$ concentrator tube. Keep on eluting the column with hexane/acetone $(9: 1, \mathrm{v}: \mathrm{v})$ until the eluate attained $10 \mathrm{~mL}$. The sample volume was reduced via rotary evaporation, changed into hexane and concentrated to $1 \mathrm{~mL}$ with a gentle purified $\mathrm{N}_{2}$ stream. Prior to transfer to GC-ECD, certain quantities of internal standard (BNB) were added.

Analytical method used Sample extracts were analyzed for PCBs by using a Varian 3800 gas chromatogram equipped with ECD detector (Varian, USA). The PCBs were separated by using a DB-5 column $(30 \mathrm{~m} \times$ $0.25 \mu \mathrm{m} \times 0.25 \mathrm{~mm})$. GC/ECD operating conditions were as follows: the injection port temperature was maintained at $225^{\circ} \mathrm{C}$ and the detector temperature was $310^{\circ} \mathrm{C}$. Column temperature was programmed at $110^{\circ} \mathrm{C}$ (hold on for $2 \mathrm{~min}$ ), increased to $280{ }^{\circ} \mathrm{C}$ at the rate of $8{ }^{\circ} \mathrm{C} / \mathrm{min}$ (hold for $5 \mathrm{~min}$ ). Hydrogen was the carrier and the flow rate was $1.0 \mathrm{~mL} / \mathrm{min}$. One microlitre volume of each sample was injected manually in the splitless mode.

Quality control Experiments were carried out in duplicate. The variation of PCBs concentrations of duplicated samples was less than $10 \%$. Two blank samples were included in every batch of samples. No PCB was detected in blank samples. PCB1242 and PCB209 standards were added to soil samples to monitor the procedures of sample extraction, cleanup and analysis. Recoveries of the PCB added to the soil samples were between 60 and $120 \%$ for Aroclor 1242, 70 and $110 \%$ for PCB209, respectively. All the values reported in this paper were corrected to achieve $100 \%$ recovery.

Numerical modeling

\section{Numerical model}

Considering adsorption and the fact there was no volatilization, the PCBs transport model was established based on the advection-dispersion equation. As to the migration of PCBs, hydrodynamic dispersion, molecular diffusion, linear equilibrium adsorption, as well as one-order degradation kinetic of PCBs have been taken into account when establishing the model. PCBs transport model should be established based on water movement model in the unsaturated zone. Thus, the governing equations of water movement in the unsaturated zone and PCBs transport are as follows.

Water flow equation:

$C(h) \frac{\partial h}{\partial t}=\frac{\partial}{\partial x}\left(K_{x} \frac{\partial h}{\partial x}\right)+\frac{\partial}{\partial z}\left(K_{z} \frac{\partial h}{\partial z}\right)+\frac{\partial K_{z}}{\partial z}$,

PCBs transport equation:

$$
\begin{aligned}
\theta R_{d} \frac{\partial c}{\partial t}= & \frac{\partial}{\partial x}\left(D_{x x} \frac{\partial c}{\partial x}\right)+\frac{\partial}{\partial z}\left(D_{z z} \frac{\partial c}{\partial z}\right)-\frac{\partial\left(q_{x} c\right)}{\partial x}-\frac{\partial\left(q_{z} c\right)}{\partial z} \\
& -\lambda \theta R_{d c} .
\end{aligned}
$$

where $C(h)$ is the water capacity $\left(\mathrm{cm}^{-1}\right), K_{x}$ and $K_{z}$ are the transverse and longitudinal hydraulic conductivities $(\mathrm{cm} / \mathrm{s})$, respectively, $D_{x x}$ and $D_{z z}$ are the transverse and longitudinal dispersion coefficients $\left(\mathrm{cm}^{2} / \mathrm{s}\right)$, respectively, $R_{d}$ is the retardation factor, $C$ is the PCBs concentration in liquid phase, $q_{x}$ and $q_{z}$ are the Darcy velocities in $x$ and $z$ directions, respectively, $\theta$ is the soil moisture (\%), $\lambda$ is the degradation coefficient $\left(d^{-1}\right)$ and $h$ is the pressure head $(\mathrm{cm})$. 
Fig. 2 Discretization of research field

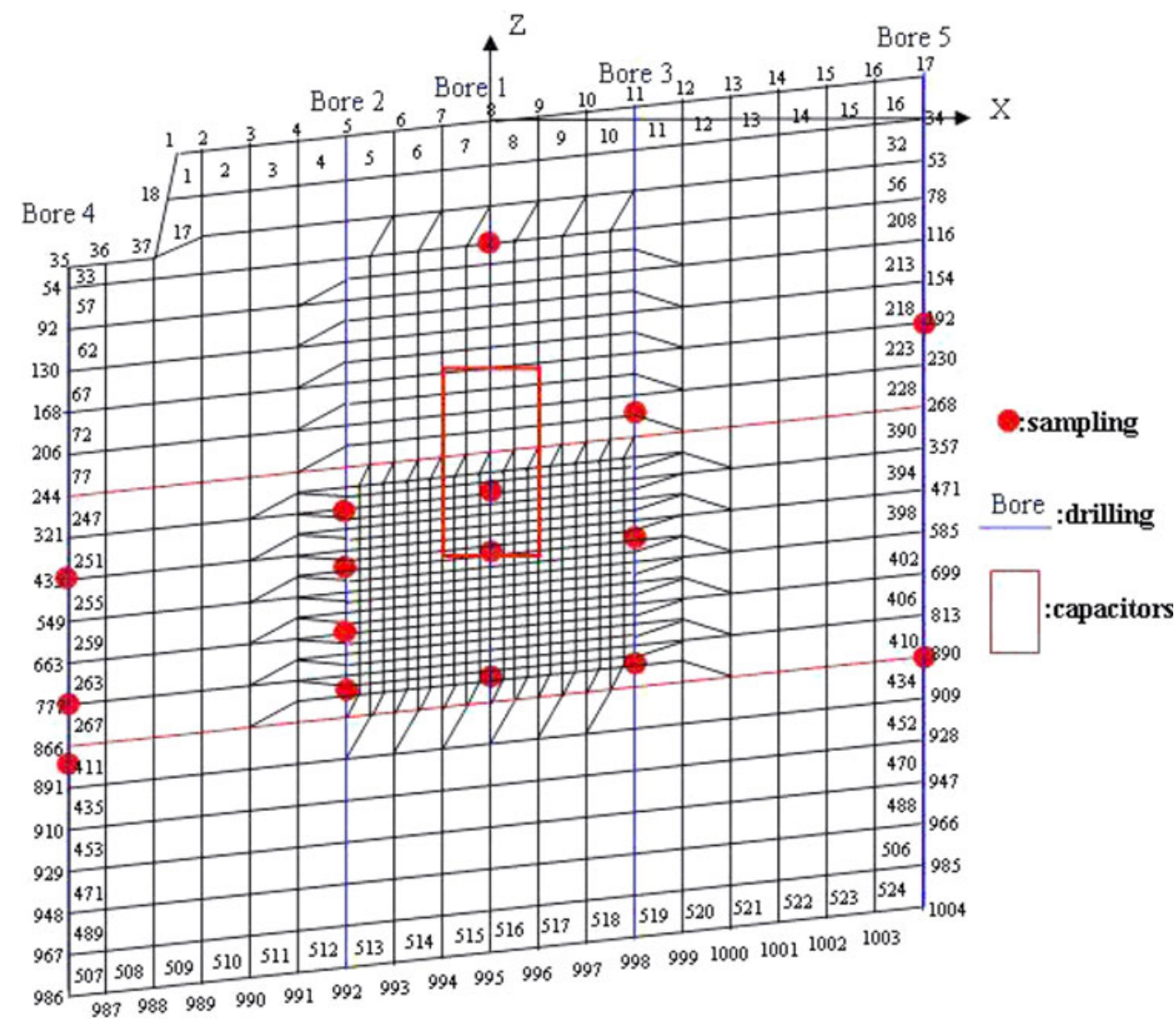

The upper boundary of water movement equation was assumed to be rainfall/evaporation-saturation boundary and the lower one was considered as constant water head (Dirichlet) boundary.

Initial condition : $h(x, z)=h_{0}(x, z), t=0$

Upper boundary condition : $\quad-K z\left(\frac{\partial h}{\partial z}-1\right)=\varepsilon, \quad z=0$.

where $\varepsilon$ is the rainfall-evaporation coefficient ( $\mathrm{cm} /$ day).

Left and right boundary condition : $\frac{\partial h}{\partial z}=0, \quad z=670 \mathrm{~cm}$

Left and right boundary condition : $\frac{\partial h}{\partial x}=0$

$$
x=-300 \mathrm{~cm}, x=300 \mathrm{~cm}
$$

The initial and boundary conditions for solute transport model are determined as:

Initial condition : $\quad c(x, z)=c_{0}(x, z), t=0$

Upper boundary condition : $\quad c(x, z, t)=c_{0}(x, z, t), z=0$
Left, right and lower boundary condition :

$$
-\left.D \frac{\partial c}{\partial n}\right|_{\Gamma 2}=0,(x, z) \in \Gamma_{2} \text {. }
$$

where $n$ is the outer normal vector.

The numerical models for water movement and PCBs transport were deduced from Eqs. (1) and (2). Finite element equations in matrix form for PCBs transport are as follows:

$\left[M_{i j}\right]\left\{\frac{d C_{i}}{d t}\right\}+\left[S_{i j}\right]\left\{C_{i}\right\}+\left\{D_{j}\right\}+\left\{Q_{j}\right\}=0$.

where

$M_{i j}=\int_{\operatorname{Re}} \theta R_{d} W_{i} \varphi_{i} d R$

$S_{i j}=\int_{\operatorname{Re}} \frac{\partial W_{j}}{\partial x}\left(\theta D_{x x} \frac{\partial \varphi_{i}}{\partial x}\right)+\frac{\partial W_{j}}{\partial z}\left(\theta D_{z z} \frac{\partial \varphi_{i}}{\partial x}\right)$

$-\left(v_{x} \varphi_{i} \frac{\partial W_{j}}{\partial x}+v_{x} \varphi_{i} \frac{\partial W_{j}}{\partial z}\right) W_{j}\left(\frac{\partial \theta}{\partial t}+\lambda \theta R_{d}\right) \varphi_{i} d R$

$D_{j}=-\int_{\operatorname{Re}} W_{i} M d R$

$Q_{j}=\int_{\mathrm{Be}} W_{i}\left\{\left(-\theta D_{x x} \frac{\partial c}{\partial x}+v_{x} c\right) n_{x}+\left(-\theta D_{z z} \frac{\partial c}{\partial z}+v_{z} c\right) n_{z}\right\} d B$. 
where $W_{i}$ is the weight function of node $i$, Re is the area of element $e, \mathrm{Me}$ is the number of elements, $\mathrm{Be}$ is the length of boundary elements, and $\varphi_{i}$ denotes basic function for $i$ th node.

Spatial discretization was conducted to solve the finite element equation, by means of quadrilateral and triangular subdivision (Fig. 2).

More elements were subdivided in field around the buried capacitors for the purpose of accurately calculating the PCBs concentration. Because limited drilling data were available, the initial conditions such as concentration and pressure head at each node were obtained through interpolation method of trend and residual.

The total simulation time and time step were determined as 100 years and 120 days, respectively. The Galerkin linear finite element method was adopted to carry out numerical computation. The Fortran Power Station was used for programming in order to carry out numerical calculation to solve the finite element equations.

\section{Parameters estimation}

The key factors which determined the transport and degradation of PCBs include precipitation, molecular diffusion coefficient, hydrodynamic dispersion coefficient, partition coefficient and degradation coefficient (half-life) (Sinkkonen and Paasivirta 2000). These data were obtained from existing reports, studies and lab-scale experiments.

Precipitation The precipitation data were referred to as climatological data from the local government (Li 2010) and the infiltration coefficient was referred to in the report by Chen (1992). For biological stability of PCBs mentioned above, long simulation time was required. The long simulation time and the semiarid condition in the contaminated field made the input of seasonal precipitation unnecessary and complicated. Assumption was made that total precipitation was equally distributed each day. The average rainfall and the infiltration coefficient are listed in Table 1.

Transport Molecular diffusion coefficient $\left(D_{\mathrm{s}}\right)$ was obtained through Hayduk and Laudie model (Hayduk and Laudie 1974). Hydrodynamic dispersion coefficient $\left(D_{\mathrm{h}}\right)$ was acquired from the 1-D soil column experiment.

Biodegradation The degradation rate of PCBs varies, depending on the quantity of chlorine atoms and the characteristics of soil (Anderson and Hites 1996). Although the biodegradation rate varies among different PCB congeners, the actual shape of peaks for different sorts of PCB through GC-ECD detection was much the same as Aroclor 1242. For this reason, it is appropriate to use mean of estimation in this study to characterize the biodegradation. The value in this simulation was obtained by means of estimation based on research on PCBs degradation in certain medium (Sinkkonen and Paasivirta 2000).

Adsorption The distribution of PCBs between soil and water is represented by the partition coefficient $K_{\mathrm{d}}$ :

$K_{\mathrm{d}}=C_{\mathrm{s}} / C_{\mathrm{e}}$.

where the $C_{\mathrm{s}}$ and $C_{\mathrm{e}}$ are the concentrations of PCBs in soil and water, respectively. The value of $K_{\mathrm{d}}$ was determined from the static distribution experiment.

Risk assessment

The modeling results were used to carry out the risk assessment before remediation and at the same time to explore the environmental impact of leaked PCBs in soil. In order to check up the remediation achievement and give risk appraisal of the remediated site, four random bores at the restored site were drilled, sampled and tested for PCBs concentrations. The same work was carried out to calculate the concentration and distribution of remaining PCBs after remediation, as well as to assess the PCBs transport and biodegradation after certain period of time.

\section{Results and discussion}

The spatial distribution of PCBs

The concentration of PCBs at different depths of nine bores before remediation is listed in Table 2. It can be found from the results that soil in Bore 1 contained the highest PCBs concentration, and this was consistent with the fact that Bore 1 was located where the capacitors had been buried. Soils in Bores 2, 3, and 7 were less contaminated than Bore 1, and, however, contained more PCBs than the other five bores. No PCBs was detected in soil sampled from Bores 4 and 5. The maximum concentration of PCBs $(1221.12 \mathrm{mg} / \mathrm{kg})$ appeared in Bore $1,3 \mathrm{~m}$ below ground surface, indicating that the most seriously contaminated field was located in Bore 1. The pollution level of PCB in this site indicated that leakage of capacitors oil was not so serious as other contaminated sites (Gibert and Martinez

Table 1 Principal parameters

\begin{tabular}{lllllll}
\hline $\begin{array}{l}\text { Annual precipitation } \\
(\mathrm{mm})\end{array}$ & $\begin{array}{l}\text { Infiltration } \\
\text { coefficient }\end{array}$ & $\begin{array}{l}\text { Daily rainfall } \\
(\mathrm{cm})\end{array}$ & $\begin{array}{l}D_{\mathrm{s}} \\
\left(\mathrm{cm}^{2} / \text { day }\right)\end{array}$ & $D_{\mathrm{h}}(\mathrm{cm})$ & $t_{\text {half }}($ year $)$ & $\begin{array}{l}K_{\mathrm{d}} \\
\left(\mathrm{cm}^{3} / \mathrm{g}\right)\end{array}$ \\
\hline 509 & 0.2 & 0.028 & 0.5 & 0.2 & 20 & 50 \\
\hline
\end{tabular}


Table 2 PCBs concentration

\begin{tabular}{|c|c|c|}
\hline Bore no. & Depth (m) & Concentration $(\mathrm{mg} / \mathrm{kg})$ \\
\hline \multirow[t]{4}{*}{1} & 1 & 0.65 \\
\hline & 3 & $1,221.12$ \\
\hline & 3.5 & 54.71 \\
\hline & 4 & 19.88 \\
\hline \multirow[t]{3}{*}{2} & 3 & 6.73 \\
\hline & 3.5 & 10.02 \\
\hline & 4.5 & 0.21 \\
\hline \multirow[t]{2}{*}{3} & 2.0 & 8.12 \\
\hline & 4.0 & 5.39 \\
\hline \multirow[t]{3}{*}{4} & 2.5 & ND \\
\hline & 3.5 & ND \\
\hline & 4.0 & ND \\
\hline \multirow[t]{2}{*}{5} & 2.0 & ND \\
\hline & 4.0 & ND \\
\hline \multirow[t]{3}{*}{6} & 2.5 & 0.66 \\
\hline & 3.5 & 0.21 \\
\hline & 4.5 & 1.01 \\
\hline \multirow[t]{3}{*}{7} & 2.5 & 5.62 \\
\hline & 3.5 & 2.84 \\
\hline & 4.5 & 4.74 \\
\hline \multirow[t]{2}{*}{8} & 2.0 & 0.50 \\
\hline & 4.0 & 1.03 \\
\hline \multirow[t]{2}{*}{9} & 2.0 & 0.77 \\
\hline & 4.5 & 0.62 \\
\hline
\end{tabular}

2009; Vasilyeva et al. 2010). Five bores were chosen to carry out the study on the two-dimensional transport and transform of PCBs in this area. Figure 3a represented the spatial distribution of PCBs on the two-dimensional profiles. Based on the chemical analysis of samples from bores and interpolation, the amounts of soil with different contamination levels were calculated by means of integration. As shown in Table 3, the total quantity of PCBs contaminated soil $(>0.5 \mathrm{mg} / \mathrm{kg})$ was about $31.28 \mathrm{~m}^{3}$. The quantity of soil to be excavated $(>1 \mathrm{mg} / \mathrm{kg}$ ) was about $14.565 \mathrm{~m}^{3}$, among which the proportion of ' $1-50 \mathrm{mg} / \mathrm{kg}$ ' soil was more than $30 \%$. Quantity and proportion of soil with PCBs concentration higher than $500 \mathrm{mg} / \mathrm{kg}$, which were regarded as high concentration hazardous PCBs waste [Control Standard on Poly Chlorinated Biphenyls for Waste Slags (GB 13015-91), Ministry of Environment, China 1991] were $2.43 \mathrm{~m}^{3}, 7.76 \%$, respectively. Quantity and proportion of soil with PCBs concentration in the range of 50 and $500 \mathrm{mg} / \mathrm{kg}$, which were regarded as hazardous PCBs waste, were $3.20 \mathrm{~m}^{3}, 17.99 \%$, respectively.

According to the Canadian Soil Quality Guidelines (2005) for PCBs and the requirement for treatment of PCBcontaminated soil in China, the buried capacitors and the contaminated soil with PCBs concentration higher than $500 \mathrm{mg} / \mathrm{kg}$ ought to be transported to the Hazardous Waste Treatment Centre (HWTC) and to be disposed by incineration (Shao 2001). The contaminated soil with PCBs concentration in the range of 1 and $500 \mathrm{mg} / \mathrm{kg}$ was to be disposed by the cheaper thermal desorption. Obviously, the choice of composite treatment technology based on the calculation of amount of soil with different contamination level has cut down the overall expense.

Model calibration

The batch of capacitors was buried in this area about 30 years ago according to the data derived from local power department. Although no accurate data with respect to the initial distribution of contamination were available, it could be assumed that the PCBs contamination 30 years ago might be located in the $0.75 \times 2 \mathrm{~m}$ rectangle field (Fig. 3b), where the capacitors were buried, since the theft happened soon after the capacitors' burial.

The initial quantity of PCBs was calculated based on the amount remained in soil at present and on the degradation
Fig. 3 a Measured concentration of PCBs and b calculated concentration of PCBs
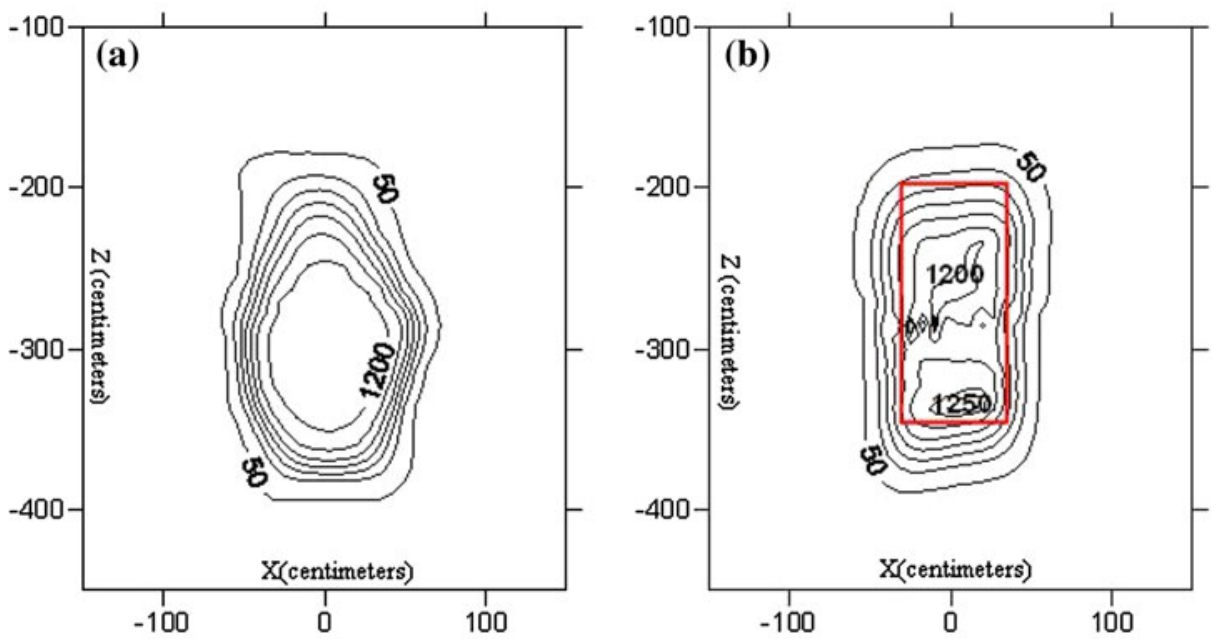
Table 3 Quantity and proportion of soil at different contamination level

\begin{tabular}{|c|c|c|c|c|c|c|c|c|c|}
\hline & \multirow[t]{2}{*}{ Concentrations $n(\mathrm{mg} / \mathrm{kg})$} & \multicolumn{2}{|l|}{0 year } & \multicolumn{2}{|c|}{10 year } & \multicolumn{2}{|c|}{30 year } & \multicolumn{2}{|c|}{50 year } \\
\hline & & $\mathrm{m}^{3}$ & $\%$ & $\mathrm{~m}^{3}$ & $\%$ & $\mathrm{~m}^{3}$ & $\%$ & $\mathrm{~m}^{3}$ & $\%$ \\
\hline \multirow[t]{4}{*}{ Quantity and proportion of soil before remediation } & $<1$ & 16.75 & 53.55 & 19.59 & 62.63 & 22.69 & 72.54 & 25.39 & 81.17 \\
\hline & $1-50$ & 8.9 & 28.44 & 7.25 & 23.18 & 5.11 & 16.34 & 3.67 & 11.73 \\
\hline & $50-500$ & 3.20 & 10.23 & 2.53 & 8.09 & 1.89 & 6.04 & 1.33 & 4.25 \\
\hline & $>500$ & 2.43 & 7.76 & 1.91 & 6.11 & 1.59 & 5.08 & 0.89 & 2.84 \\
\hline \multirow[t]{4}{*}{ Quantity and proportion of soil after remediation } & $<0.05$ & 15.14 & 48.4 & 17.04 & 54.48 & 21.07 & 67.36 & 25.55 & 81.68 \\
\hline & $0.05-0.5$ & 13.51 & 43.2 & 12.17 & 38.91 & 8.98 & 28.71 & 5.12 & 16.37 \\
\hline & $0.5-1$ & 2.01 & 6.42 & 1.64 & 5.24 & 0.98 & 3.13 & 0.51 & 1.63 \\
\hline & $>1$ & 0.62 & 1.98 & 0.43 & 1.37 & 0.25 & 0.80 & 0.10 & 0.32 \\
\hline
\end{tabular}

coefficient. Assumption was made that all of the PCBs were evenly distributed around the buried capacitors (rectangular field in Fig. 3b). The tested results of PCBs distribution are plotted in Fig. 3a. Based on the hypothetical value, numerical calibration was carried out by using established model in order to verify the effectiveness of this model on prediction of PCBs transport and degradation in soil, as well as the correctness of parameters. The contour map as shown in Fig. $3 \mathrm{~b}$ indicated that relatively satisfactory simulation results were obtained. Both the shape and the area of contamination of simulation were consistent with the calculated value except for the maximum contour. The maximum contour $(1,200 \mathrm{mg} / \mathrm{kg})$ of measured value covered a larger and more extended area and the calculated one was discontiguous and cracked. This was primarily due to the selected interpolation method which makes a little difference between measured and actual value. A smaller grid size of space as well as adequate data would make the prediction much more accurate.

Figure 4 indicated the change of averaged concentration at each node as a function of depth. It was obviously that the PCBs contamination was located between the 2.2 and $3 \mathrm{~m}$ below the surface. It can also be found from the results that the curve of simulated value fitted well to the measured value except the maximum value. This may be caused by the inaccurate assessment of the amount of capacitor oil leakage. In addition, probably due to a smaller diffusion coefficient was used, the speed of PCBs transport downward in simulation result was found to be slightly slower than the measured value.

\section{Risk assessment before remediation}

Figure 5 denoted the PCBs transport and degradation in 100 years before remediation and Fig. 6 depicted the change of averaged concentration at each node as a function of depth. As shown in Fig. 5a, b, the transport of PCBs downward in the first 10 years was negligible. During

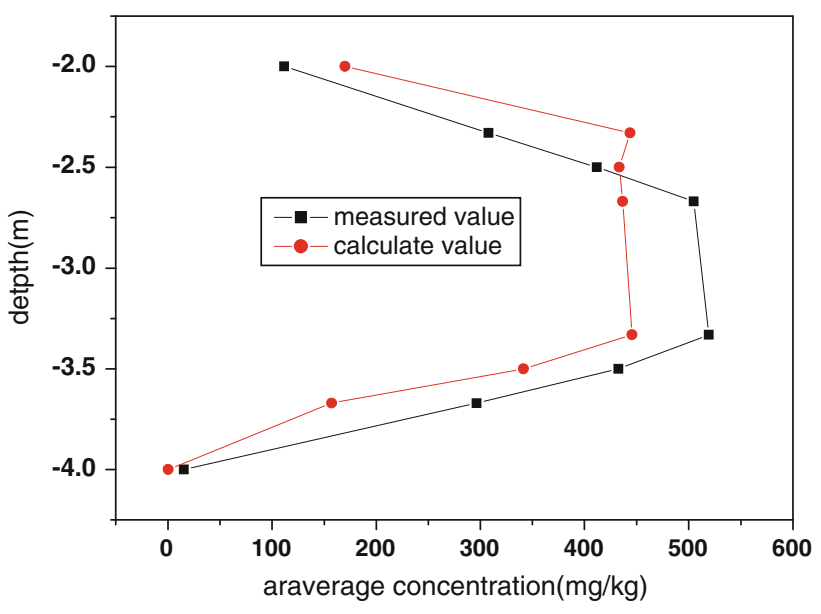

Fig. 4 Change of PCBs concentration with depth

30 years the distance of capacitors oil transport downward was less than $30 \mathrm{~cm}$ (Figs. 5c, 6). Even after 100 years of simulation the cumulative transport distance was no more than $100 \mathrm{~cm}$ (Fig. 5f). The transport speed obtained from this simulation was slower than the experimental results carried out by Zhu and Xia (2003), who used artificial contaminated soil to study the transport of PCBs in columns. The extremely slow transport speed of PCBs in this study is primarily due to the large value of $K_{\mathrm{d}}$, which determined the distribution of organics between soil and water, and also due to a smaller annual rainfall in the semiarid region of China and the high fraction of fine particulates in soil, which made the water flow very slow. Additionally, compared to the artificial or newly contaminated soil, the organics in aged soil tended to adsorb contaminants more tightly and irreversibly ( $\mathrm{Li}$ and Chen 2010). Since there was no difference in matric and gravity potential of soil between this area and the adjacent area, relatively low speed of transverse water flow and no horizontal transport were observed.

Buried deep in the ground, it was hard for the contaminants to evaporate or to be absorbed by roots of shrubs 
(Kohne et al. 2009; Mirbagheri and Monfared 2009). Under this condition, PCBs could only be degraded by proper microbe (Kohne et al. 2009). It could be seen from the simulation results (Figs. 5, 6) that the biodegradation of PCBs oil in soil was very slow. After 50 years more than $2 \mathrm{~m}^{3}$ soil with concentration higher than $50 \mathrm{mg} / \mathrm{kg}$ would remain in soil, as shown in Table 3. Even after 100 years there was over $30 \mathrm{mg} / \mathrm{kg}$ concentration of PCBs remaining in the medium if no treatment was carried out. Nevertheless, Fig. 6 shows that the effect of degradation was more visible than the PCBs movement caused by solute transport. Considering the simulation during the 100 years, the contamination plume expanded during first 30 years and then shrank gradually. Molecular diffusion of PCBs in water caused the amplification of contamination plume while biodegradation affected adversely. Based on the simulation results it can be seen that the main mechanism of PCBs' disappearance around the capacitors burial site was biodegradation. Additionally, molecular diffusion played an important role in the expansion of PCBs contamination plume during the initial stage. Because of the lack of rainfall and the strong adsorption of PCBs onto soil, the transport of PCBs in the soil in semiarid region grows much slower (Hodak Kobasic et al. 2008). Although the transport speed of PCBs in soil in semiarid region was so slow that hardly any PCBs were able to migrate downward before they were completely biodegraded by microbe, the highly PCB-contaminated soil would stay underground for a long time (no less than 50 years) due to relatively slow biodegradation rate.

Risk appraisal after remediation

PCBs remaining and the pollutants transport in 100 years after remediation are shown in Fig. 7a-c. Figure 7 a shows the distribution of remaining PCBs after the excavation for disposal by incineration and thermal desorption.

No PCBs contamination was detected in the excavated field. Although the contaminated soil was not completely removed by excavation because of economic consideration,
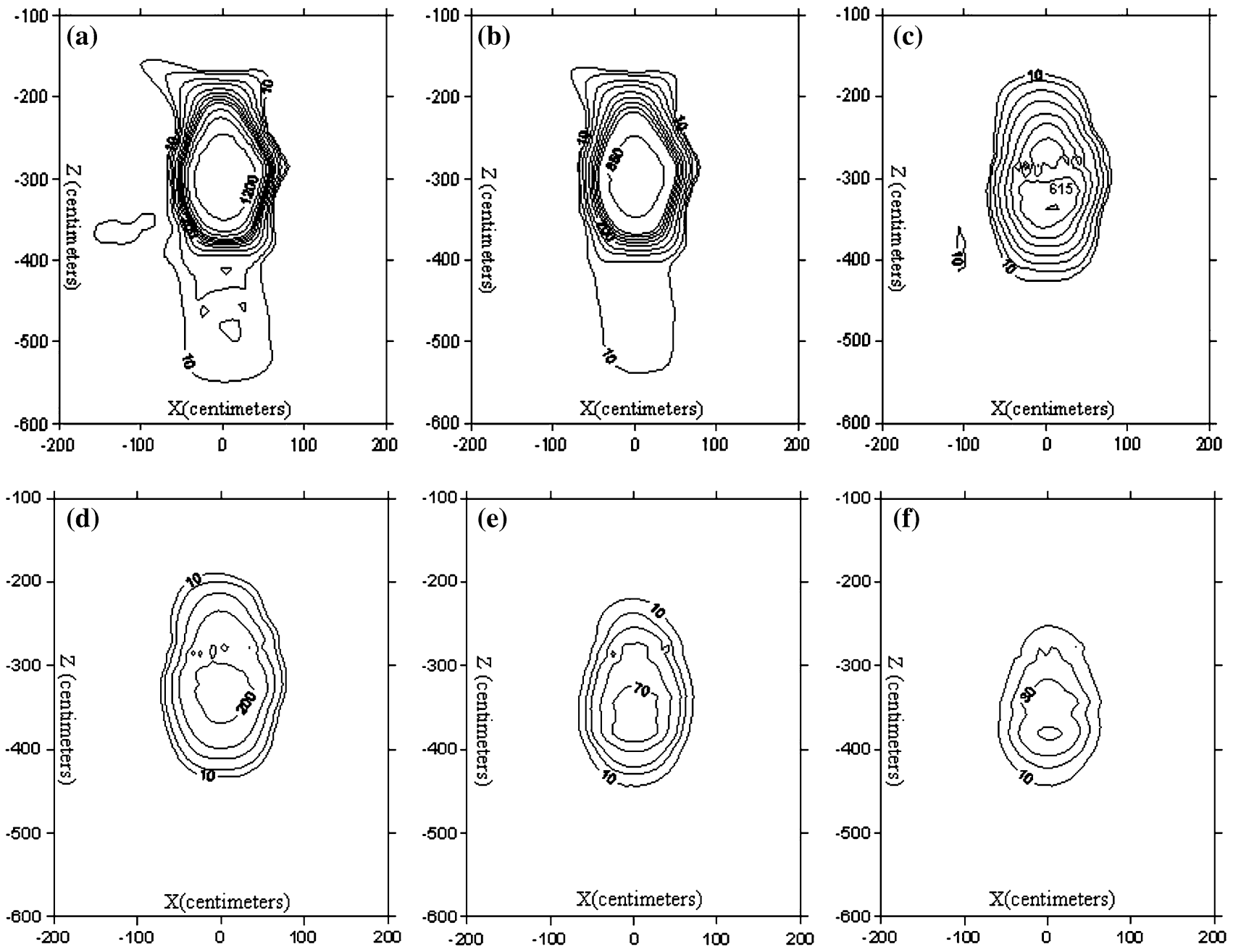

Fig. 5 a Initial concentration, b 10 years later, c 30 years later, d 50 years later, e 80 years later, f 100 years later 


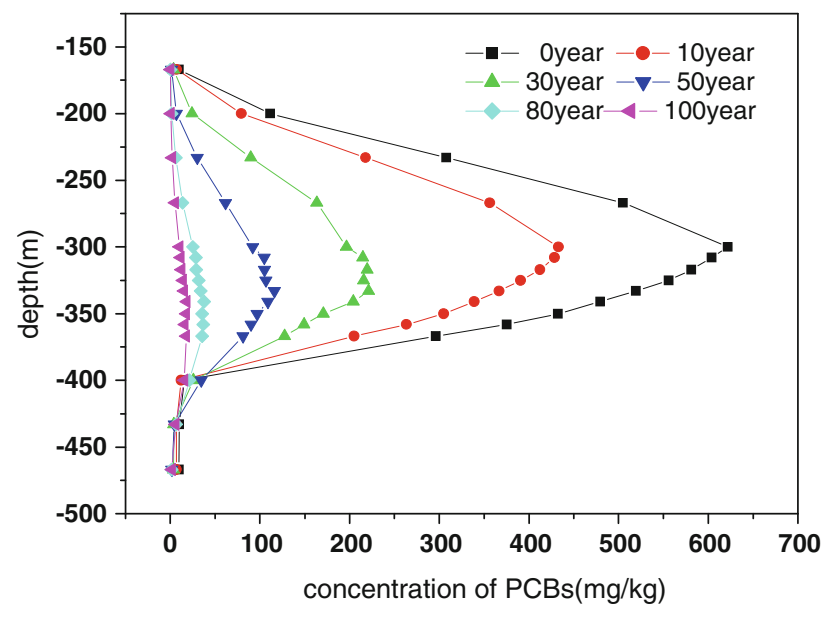

Fig. 6 Change of PCBs concentration with depth

the PCBs concentration of soil in the study field was reduced below $1 \mathrm{mg} / \mathrm{kg}$ and the amounts of soil with PCBs concentration higher than $0.5 \mathrm{mg} / \mathrm{kg}$ were decreased by over $90 \%$ (Fig. 7a; Table 3).

The simulation results of PCBs migration after 30 years (Fig. 7b; Table 3) indicated that all of the contaminated soil (maximum $0.319 \mathrm{mg} / \mathrm{kg}$ ) were restored to comply with the standard for agricultural use $(0.5 \mathrm{mg} / \mathrm{kg}$, Ministry of Environment, China 1991). As shown in Table 3 and Fig. 7c, after 50 years the PCBs concentration of over $80 \%$ soil would be reduced to background level $(50 \mu \mathrm{g} / \mathrm{kg})$ (Li 2010). Based on the analysis of the remaining PCBs contamination and the simulation, the remediation has successfully removed most of the contaminants, which pose great risk to the local ecological environment and human health. Results of simulation indicate that the remaining PCBs in soil would hardly cause any harm in the future due to the relatively low PCBs concentration. Both the concentration of remaining PCBs and the simulation results decades later indicate a successful and effective rehabilitation work.

\section{Conclusion}

In this study, PCB-contaminated soil around buried capacitors was sampled through site drilling. Test results showed that soil at depth of $3 \mathrm{~m}$ below ground in Bore 1 contained the highest PCBs concentration while no PCBs were detected in Bores 4 and 5. Quantity and proportion of soil with PCBs concentration higher than $500 \mathrm{mg} / \mathrm{kg}$, which were regarded as high concentration hazardous PCBs waste were $2.43 \mathrm{~m}^{3}, 7.76 \%$, respectively, and of soil with PCBs concentration higher than $50 \mathrm{mg} / \mathrm{kg}$ and lower than $500 \mathrm{mg} / \mathrm{kg}$, which were regarded as hazardous PCBs waste, were $3.20 \mathrm{~m}^{3}, 17.99 \%$, respectively. The excavation-incineration and thermal desorption was chosen to remediate the burial site.

Two-dimensional PCBs transport model was established and simulation was carried out to study the migration of PCBs by using part of test data. The numerical modeling results suggest that the solute transport model could effectively simulate the transport and biodegradation of PCBs in soil. The emphases in simulation were to calibrate the PCBs transport model and assess the environmental impact of removed PCB-containing power capacitor burial site.

Based on the PCB-contaminated soil, numerical simulation was conducted to investigate the transport and disappearance of contaminants. Results of simulation indicate that after 30 years, PCBs plume moved downward for less than $30 \mathrm{~cm}$ and that after 100 years PCBs plume moved downward for no more than $100 \mathrm{~cm}$. Molecular diffusion plays an important role in plume expansion in initial time and biodegradation would take opposite effect which leads
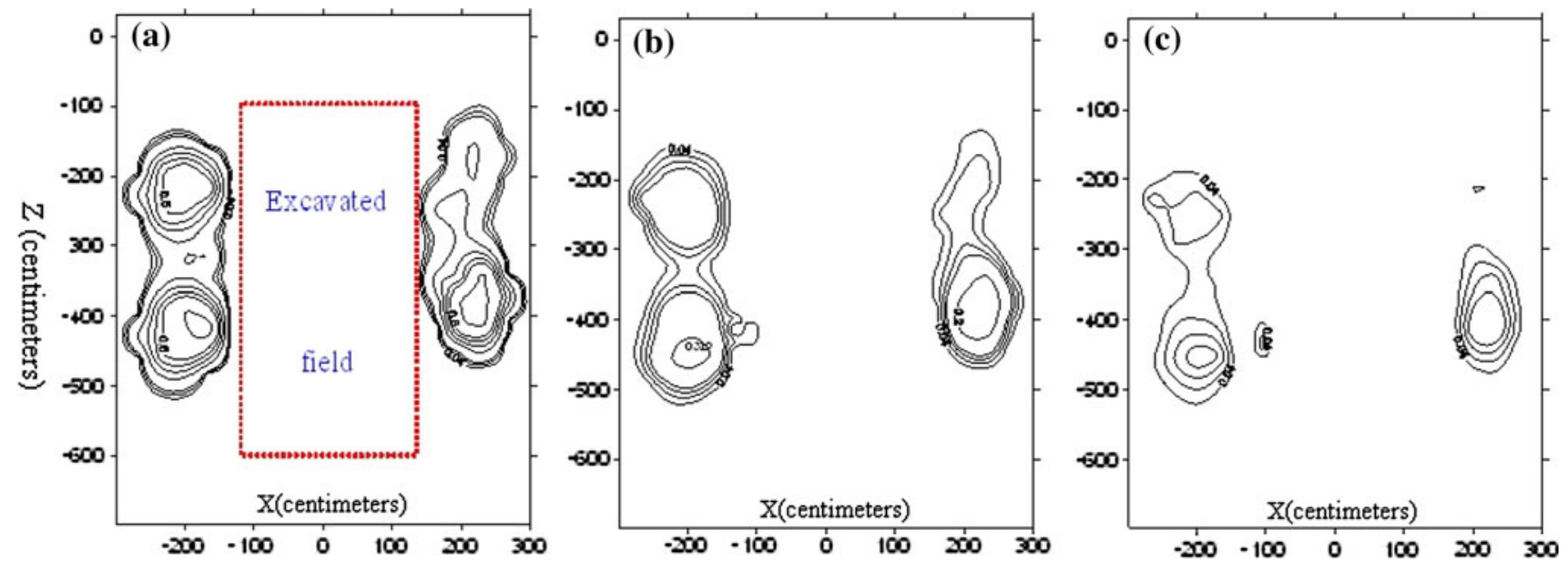

Fig. 7 a Initial concentration (after remediation), b 30 years later (after remediation), c 50 years later (after remediation) 
to gradual shrinking of plume in a period of time. The primary mechanism of PCBs' disappearance is biodegradation, although the $t_{\text {half }}$ of PCBs is larger than most of organics. No horizontal movement of pollutants was observed in this simulation.

The contrast of simulation results between contaminated site without remediation and that with remediation measures suggests an effective reduction of contamination by excavation-incineration and thermal desorption. More than $90 \%$ of the soil in this field was restored to meet the requirement for agricultural use. In 30 years all of the soil could be agriculturally used and in 50 years the concentration in $80 \%$ of soil were reduced to background level. The conducted numerical simulation of PCBs transport using limited data obtained from actual field indicates a successful, effective rehabilitation work and a feasible alternative for risk appraisal of organics such as PCBs. The procedure could also be applied to other sites restoration to support the choice of appropriate technology and to estimate the remediation results.

Acknowledgments The work reported in this paper was supported by the National Natural Science Foundation of China (41272248). We would like to thank Professor Shulin Ding, a Fulbright Visiting Professor in the United States, for his encouragement of this study.

\section{References}

Anderson PN, Hites RA (1996) System to measure relative rate constants of semivolatile organic compounds with hydroxyl radicals. Environ Sci Technol 30(1):301-306

Ballschmiter K, Zell M (1980) Analysis of poly-chlorinated biphenyls (PCB) by glass capillary gas chromatography. Fresen J Anal Chem 302(1):20-31

Blais JM, Schindler DW, Muir DCG, Kimpe LE, Donald DB, Rosenberg B (1998) Accumulation of persistent organochloride compounds in mountains of western Canada. Nature 359(8):585-588

Chatupote W, Paapitukkul N (2005) Regional assessment of nutrient and pesticide leaching in the vegetable production area of rattaphum catchment, Thailand. Water Air Soil Poll 5(1-2):165-173

Chen JJ (1992) Water flow and numerical simulation of nuclide migration in unsaturated loess, $\mathrm{PhD}$ dissertation. China University of Geosciences, Beijing

Cok I, Satiroglu MH (2004) Polychlorinated biphenyl levels in adipose tissue of primiparous women in Turkey. Environ Int 30(1):7-10

Devasena M, Nambi IM (2010) Migration and entrapment of mercury in porous media. J Contam Hydrol 117(1-4):60-70

Fagbote EO, Olanipekun EO (2010) Levels of polycyclic aromatic hydrocarbons and polychlorinated biphenyls in sediment of bitumen deposit impacted area. Int J Environ Sci Tech 7(3): $561-570$

Fava L, Orru MA (2005) Pesticide metabolites as contaminants of groundwater resources: assessment of the leaching potential of endosulfan sulfate, 2, 6-dichlorobenzoic acid, 3, 4-dichloroaniline, 2, 4-dichlorophenol and 4-chloro-2-methylphenol. Microchem J 79(1-2):207-211

Fouial-Djebbar D, Badjah-Hadj Ahmed AY, Budzinski H (2010) Determination of organochlorine compounds in coastal marine sediments from the southern west of the Mediterranean Sea. Int J Environ Sci Technol 7(2):271-280

Gibert AO, Martinez LX (2009) Changes of heavy metal and PCB contents in surficial sediments of the Barcelona harbour after the opening of a new entrance. Water Air Soil Poll 204(1-4): 271-284

Hayduk W, Laudie H (1974) Prediction of diffusion coefficients for non-electrolytes in dilute aqueous solutions. Alche J 20: $611-615$

Hodak Kobasic V, Calic V, Picer M, Picer N (2008) Transport of $\mathrm{PCBs}$ with leachate water from contaminated soil. Chemosphere 73:143-148

Ismail BS, Ngan CK (2004) Leaching potential of pesticides in a vegetable farm in the Cameron Highlands Malaysia. B Environ Contam Tox 72(4):836-843

Kohne JM, Kohne S, Simunek J (2009) A review of model applications for structured soils: b) Pesticide transport. J Contam Hydrol 104(1-4):36-60

Li XJ (2010) An experimental research and numerical simulation on the migration law of PCBs in the soil, master's thesis, Taiyuan university of technology

Li HL, Chen JJ (2010) Distribution of polycyclic aromatic hydrocarbons in different size fractions of soil from a coke oven plant and its relationship to organic carbon content. J Hazard Mater 176(1-3):729-734

Li S, Chen JJ, Meng ZL (2004) Advance in handing and disposal of polychlorinated biphenyls at home and abroad. Sci Technol Dev 2:26-29

Lu Y (2009) Experiment research of in situ cosolvent flushing of polychlorinated biphenyls from soil, master's thesis, Beijing Normal University

Ministry of Environment China (1991) Control standard on poly chlorinated biphenyls (PCBs) for waste slags (GB13015-91). http://baike.baidu.com/view/3023496.htm. Accessed 16 Dec 2010

Mirbagheri SA, Monfared SAH (2009) Pesticide transport and transformation modeling in soil column and groundwater contamination prediction. Int J Environ Sci Tech 6(2):233-242

Monosson E, Ashley JTF, McElroy AE, Woltering D, Elskus AA (2003) PCB congener distributions in muscle, liver and gonad of Rundulus heteroclites from the lower Hudson River Estuary and Newark Bay. Chemosphere 52:777-787

National Guidelines and Standards Office (2005) Canadian soil quality guidelines for polychlorinated biphenyls (PCBs). www.ec.gc.ca/ceqg-rcqe/. Accessed 16 Dec 2010

Shao CY (2001) Polychlorinated biphenyls management and pollution prevention (GB 13015-91). Persistent organic pollutants controlled symposium, Beijing, Ministry of Environmental Protection of the People's Republic of China

Shikiya M, Barcikowski W, Kahn MI (1988) Analysis of ambient data from potential toxics 'hotpoints' in the South Coast Air Basin. South Coast Air Quality Management District

Sinkkonen S, Paasivirta J (2000) Degradation half-life times of PCDDs, PCDFs and PCBs for environmental fate modeling. Chemosphere 40(9-11):943-949

The Environment Programme of the United Nation (2000) Survey of currently available nonincineration PCB destruction technologies. http://irptc.unep.ch/pops/pdf/pcbrpt.pdf. Accessed 16 Dec 2010

The Environment Programme of the United Nations (1998) Inventory of worldwide PCB destruction capacity. http://irptc.unep.ch/ pops/pdf/pcbrpt.pdf. Accessed 16 Dec 2010

United States Environmental Protection Agency (1987) National air toxics information report. Qualitative and quantitative carcinogenic risk assessment. EPA 450/5-87-003, US Environmental Protection Agency and STAPPA/ALAPCO, Washington, p 11.1-11.6 
United States Environmental Protection Agency (1987) Public Health Levels for PCBs in Indoor School Air. US Environmental Protection Agency and STAPPA/ALAPCO, Washington. http://www.epa.gov/pcbsincaulk/maxconcentrations.htm. Accessed 16 Dec 2010

Vasilyeva GK, Strijakova ER, Nikolaeva SN, Lebedev AT, Shea PJ (2010) Dynamics of PCB removal and detoxification in historically contaminated soils amended with activated carbon. Environ Pollut 158(3):770-777

Zhou ML (1988) Stratum of China. The geological publishing house, Beijing, pp 134-136

Zhu NK, Xia XJ (2003) The disappearance and transfer behavior of PCBs bestrewed into semi field soil systems. Environ Sci (China) 24(4):159-160 